Made available courtesy of University of Chicago Press: http://www.amnat.org/

***Reprinted with permission. No further reproduction is authorized without written permission from the University of Chicago Press.

This version of the document is not the version of record. Figures and/or pictures may be missing from this format of the document. ${ }^{* * *}$

VOL. 175, NO. 3 THE AMERICAN NATURALIST MARCH 2010

\title{
Floral Reflectance, Color, and Thermoregulation: What Really Explains Geographic Variation in Thermal Acclimation Ability of Ectotherms?
}

\author{
Elizabeth P. Lacey, ${ }^{1, *}$ Mary E. Lovin, ${ }^{1}$ Scott J. Richter, ${ }^{2}$ and Dean A. Herington ${ }^{3}$ \\ 1. Department of Biology, University of North Carolina, Greensboro, North Carolina 27402; 2. Department of Mathematics and \\ Statistics, University of North Carolina, Greensboro, North Carolina 27402; 3. EMC Corporation, Research Triangle Park, Durham, \\ North Carolina 27709
}

Submitted February 26, 2009; Accepted October 12, 2009; Electronically published January 25, 2010

Online enhancements: appendixes.

\begin{abstract}
Adaptive phenotypic plasticity in thermally sensitive traits, that is, thermal acclimation, generally increases with increasing latitude and altitude. The presumed explanation is that high-latitude/ altitude organisms have evolved greater acclimation ability because of exposure to greater temperature fluctuations. Using a conceptual model of the thermal environment during the reproductive season, we tested this hypothesis against an alternative that plasticity is greater because of increased exposure to specific temperatures that strongly select for thermal acclimation. We examined geographic variation in floral reflectance/color plasticity among 29 European populations of a widespread perennial herb, Plantago lanceolata. Individuals partially thermoregulate reproduction through temperature-sensitive plasticity in floral reflectance/color. Plasticity was positively correlated with latitude and altitude. Path analyses support the hypothesis that the thermal environment mediates these geographic effects. Plasticity declined as seasonal temperature range increased, and it increased as duration of the growing season shortened and as the proportion of time exposed to temperatures favoring thermoregulation increased. Data provide evidence that floral reflectance/color plasticity is adaptive and that it has evolved in response not to the magnitude of temperature variation during the reproductive season but rather to the relative exposure to low temperatures, which favor thermoregulation.
\end{abstract}

Keywords: thermal acclimation, phenotypic plasticity, floral reflectance, geographic variation, ectotherm, Plantago lanceolata.

\section{Introduction}

Janzen's (1967) influential article, entitled "Why Mountain Passes Are Higher in the Tropics," provided a conceptual framework for studying how climate influences the evolution of temperature-sensitive traits. He argued that ther-

* Corresponding author; e-mail: eplacey@uncg.edu.

Am. Nat. 2010. Vol. 175, pp. 335-349. (c) 2010 by The University of Chicago. 0003-0147/2010/17503-51110\$15.00. All rights reserved.

DOI: $10.1086 / 650442$ mal acclimation ability, and thus the ability to cross mountain passes, should be greater in temperate species because seasonal temperature variation is greater in temperate regions and because thermal acclimation should evolve to be directly proportional to the magnitude of temperature variation experienced by organisms. The argument applies also to altitudinal gradients (Ghalambor et al. 2006).

Janzen's premise that thermal acclimation ability has evolved in response to the magnitude of temperature variation, which we will refer to as the temperature variation hypothesis (TVH), was an early statement about the evolution of phenotypic plasticity in temporally variable environments. Environmental variability is believed to be a necessary condition for plasticity to be favored over nonplasticity, and this belief is supported by predictions of mathematical models and data from many empirical studies (e.g., Levins 1968; Via and Lande 1985; Schlichting 1986; Scheiner 1993; Kingsolver and Huey 1998; Schlichting and Pigliucci 1998; West-Eberhard 2003; DeWitt and Scheiner 2004). Large-scale geographic studies provide evidence for the TVH, and thus adaptive plasticity, in that they show positive correlations between plasticity, latitude/ altitude, and seasonal temperature variation (Ghalambor et al. 2006). However, conclusions that can be drawn from such correlations are limited because these studies have rarely considered alternative explanations for the observed correlations.

One alternative hypothesis that might also explain the correlations concerns variation in the intensity of selection. Selection intensity could change across the range of environments that a population experiences during the year or growing season. In such situations, plasticity should be favored in environments where the frequency of intense selection is high but not where the frequency is low (Gomulkiewicz and Kirkpatrick 1992; Kingsolver et al. 2001; Arnold and Peterson 2002). Rarely have plasticity studies 
measured selection intensities in nature (Weis and Gorman 1990; Huber et al. 2004), and to our knowledge, previous large-scale geographic studies have not tested the possibility that variation in selection intensity could explain large-scale patterns of thermal acclimation and plasticity in temperature-sensitive traits. Additionally, large-scale studies of thermal acclimation have focused primarily on interspecific comparisons of vertebrates and Drosophila (Addo-Bediako et al. 2000; Cunningham and Read 2002; Ghalambor et al. 2006; Naya et al. 2008; Ragland and Kingsolver 2008). Large-scale intraspecific studies and studies of acclimation in other groups of organisms are rare (Gaston and Chown 1999; Cunningham and Read 2002; Collinge et al. 2006; Ghalambor et al. 2006; Ragland and Kingsolver 2008).

To examine thermal acclimation (adaptive temperaturesensitive plasticity) and its underlying cause(s) further, we conducted a study of temperature-sensitive plasticity in floral reflectance/color in Plantago lanceolata (Plantaginaceae). Individuals partially thermoregulate reproduction by changing floral reflectance/color. Our goals were to (1) describe the latitudinal, altitudinal, and continental variation in reflectance/color plasticity; (2) look for evidence of adaptive divergence in response to temperature; and (3) test alternative hypotheses about the role of the thermal environment in explaining the divergence. We examined the pattern of floral reflectance/color across latitudinal, altitudinal, and continental gradients in Western Europe to test whether plasticity increases with latitude/altitude. Also, because maritime regions generally fluctuate less in temperature than do interior regions of continents, we tested the hypothesis that plasticity is positively correlated with distance to the coast. To assess the role of temperature in producing the geographic patterns, we developed a conceptual model of the thermal environment during a reproductive season. The model took into account not only the seasonal range of temperatures but also the changing benefit of thermoregulation across that temperature range.

\section{Floral Reflectance and Thermoregulation in Plantago lanceolata}

Floral reflectance in Plantago lanceolata L. (ribwort plantain, English plantain), a common temperate perennial herb native to Eurasia, is determined by ambient temperature during the embryonic development of flowers in the axils of subtending leaves (Lacey and Herr 2005). Although floral reflectance of an individual flower and spike (inflorescence of tightly packed flowers) is fixed at the time of embryonic development of each flower/spike, temperature-induced changes are reversible at the individualplant level. Thus, throughout a reproductive season, for example, April to August/September in North Carolina, an individual changes the reflectance/color of newly produced flowers/spikes in response to changes in ambient temperature (Lacey and Herr 2005). On average, an individual produces poorly reflective/darkly colored flowers at cool temperatures, for example, spring and autumn, but highly reflective/light-colored flowers at warm temperatures, for example, midsummer. The greatest observed responses to temperature occur in the visible portion of the spectrum (peak at $550 \mathrm{~nm}$ ), which we can detect as color, and in the near-infrared (NIR) region (750-850 nm), which our eyes cannot detect (Lacey and Herr 2005; Umbach et al. 2009). A $5^{\circ} \mathrm{C}$ temperature change produces visible color change between current and new spikes within a week. This temperature sensitivity, not observed in leaves (E. P. Lacey, unpublished data), provides a plant with partial ability to thermoregulate its reproduction. Poorly reflective/darker flowers and spikes get warmer in the sun (Lacey and Herr 2005).

Reflectance plasticity and, therefore, thermoregulatory ability are genetically variable within and among populations (Lacey and Herr 2005; Umbach et al. 2009). In general, all genotypes are highly reflective at warm ambient temperatures but differ in their ability to reduce reflectance when ambient temperature drops. Some genotypes have shown negligible temperature-sensitive plasticity; that is, they are essentially nonplastic and produce only highly reflective flowers/spikes.

Previous experiments suggest that reflectance/color plasticity in North Carolina has evolved in response to seasonal (i.e., temporal) changes in temperature and predation pressure during the reproductive season. Offspring produced under warm temperatures, that is, later in the season, are more fit than are offspring produced at cool temperatures, that is, earlier in the season (Lacey and Herr 2000). However, seed predation increases through the reproductive season (Lacey et al. 2003). Consequently, plants that have the ability to increase internal flower and developing fruit temperatures by reducing floral reflectance during the cool spring months should be favored because they can produce offspring early when predators are scarce and can also produce offspring that are more fit than they would be in the absence of floral warming (Lacey and Herr 2005).

The experiment described here tests the hypothesis that reflectance/color plasticity has evolved in response to the thermal environment during the reproductive season. The hypothesis predicts that populations found along latitudinal/altitudinal/continental gradients should differ in plasticity and that the thermal environment mediates these latitudinal/altitudinal/continental effects. The TVH predicts that plasticity should be positively correlated with the range of temperatures experienced by individuals during the reproductive season. The variable selection intensity 
hypothesis (VSIH) predicts a positive correlation between plasticity and proportion of time exposed to temperatures strongly favoring thermoregulation.

\section{Conceptual Model of the Thermal Environment during Reproduction}

In general, a reproductive season can be characterized by four parameters: duration of the season, total temperature range, mean temperature, and total degree days (the first three are shown in fig. 1). The duration defines the phenological window within which a plant reproduces. The temperature range measures thermal variation that an individual experiences within that window. Environmental variability has most often been measured in terms of environmental range or variance (e.g., Janzen 1967; Lynch and Gabriel 1987; Gabriel and Lynch 1992; Gavrilets and Scheiner 1993a, 1993b; Gilchrist 1995). We used range as our measure of temperature variation. Together, duration and range define the predictable curvilinear shape of seasonal temperature change about the mean during a reproductive season (e.g., fig. 2). Total degree days measures the heat accumulation over the reproductive season. To test the hypothesis that reflectance plasticity has adapted to the thermal environment, we considered thermal variability over the entire reproductive season. Doing so captured the variation in ambient temperature during both early floral development, when temperature determines a particular reflectance/color phenotype, and flowering and fruit development, when temperature influences offspring production and fitness. We used data for degree months and flowering season as our proxies for degree days and reproductive season, respectively.

Our model also addressed how the fitness consequence of a change in body temperature might change across the range of seasonal temperatures that an individual experiences. Temperature influences all fundamental metabolic processes, for example, respiration and photosynthesis. However, recent studies have shown that the strength of this influence is variable. For example, the rate of cellular respiration in Plantago lanceolata, at least in roots, is limited primarily by temperature when ambient temperature is below $15^{\circ} \mathrm{C}$ but decreasingly so above $15^{\circ} \mathrm{C}$ (CoveyCrump et al. 2002). Around $25^{\circ} \mathrm{C}$, respiration rate in plants is more strongly limited by adenylates and/or substrate supply (Atkin et al. 2005). This variable influence of temperature should affect the strength of selection on traits that underlie thermoregulatory ability. Selection intensity favoring thermoregulation should be strong at temperatures where a change in body temperature could potentially produce a large fitness benefit, for example, at temperatures that strongly influence metabolic rate. Selection intensity should weaken as the potential fitness benefit wanes, for example, as the influence of temperature on metabolic rate declines.

For the reasons above, we divided the reproductive season into temperature $(\mathrm{T})$-sensitive and $\mathrm{T}$-insensitive fitness zones (fig. 1). We assumed that in the T-sensitive zone, that is, below the threshold temperature of $15^{\circ} \mathrm{C}$, a change in internal floral temperature produces a strong fitness effect, and selection intensity favoring plasticity is high. Above $15^{\circ} \mathrm{C}$, in the $\mathrm{T}$-insensitive zone, the fitness effect is weaker, and selection for plasticity is low. Theoretically,

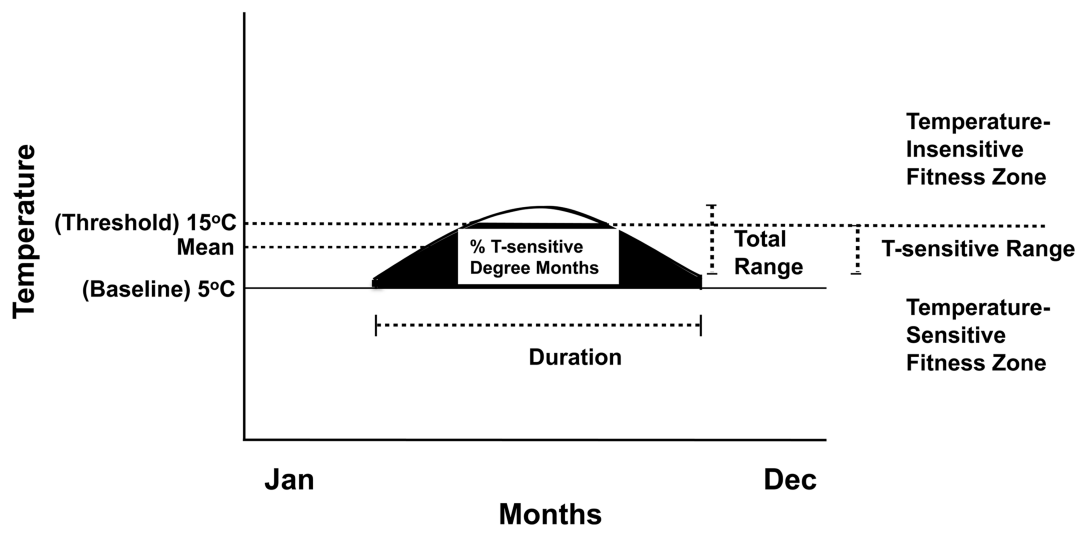

Figure 1: Conceptual model of temperature variation during a reproductive season. The model included five temperature parameters used for hypothesis testing: duration of the season, temperature range, mean temperature, temperature (T) range solely within the T-sensitive fitness zone, and proportion of degree months in the T-sensitive zone. The threshold temperature of $15^{\circ} \mathrm{C}$ divided T-sensitive and T-insensitive zones. The baseline of $5^{\circ} \mathrm{C}$ was used as a lower bound to calculate degree months. See textual description of model for additional information. Temperature parameters for all sample populations are given in appendix A in the online edition of the American Naturalist. 


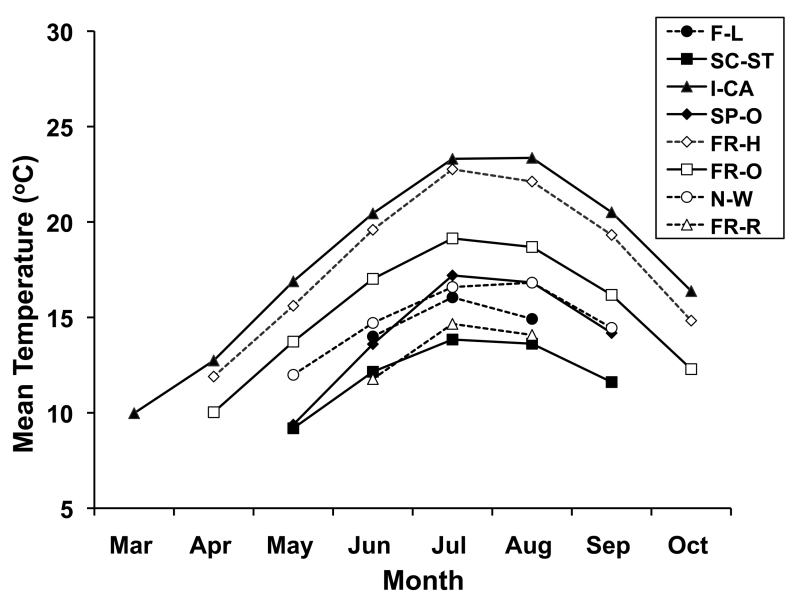

Figure 2: Estimated 30-year mean monthly temperatures during the flowering season for eight sample population sites. See "Methods" for estimation procedure. See table 1 for site name abbreviations.

there should exist a second T-sensitive zone near $40^{\circ} \mathrm{C}$. We did not include this zone because mean monthly temperature data for all sample populations never exceeded $28^{\circ} \mathrm{C}$ (e.g., fig. 2 ).

Dividing the reproductive season into $\mathrm{T}$-sensitive (highly selective) and T-insensitive (weakly selective) zones allowed us to create two additional thermal parameters characterizing the reproductive season: the temperature range solely within the T-sensitive zone and the proportion of total degree months in the T-sensitive zone (fig. 1). These two measures, along with range, duration, and mean, constituted the five temperature parameters that we used to characterize the thermal environment and to test the TVH, that reflectance plasticity is increasingly favored as seasonal temperature range increases, and the VSIH, that plasticity is increasingly favored as relative exposure to highly selective temperatures increases. We also tested a third hypothesis that plasticity is increasingly favored as the range of highly selective temperatures increases.

\section{Methods}

Hypothesis testing involved four steps. First, we quantified reflectance and reflectance plasticity separately for flower buds and developing fruits, and then we examined the relationships between these plasticity measures and latitude, altitude, and distance to the coast. Second, we conducted a principal components analysis (PCA) of the five temperature parameters to reduce the parameters to two composite indexes that served as proxies for the thermal environment. Proxies were used in step three, path analyses (structural equation modeling), which tested the hypoth- esis that the thermal environment mediates latitudinal/ altitudinal/continental effects on plasticity. Fourth, we examined the relationships between plasticity and each temperature parameter in our model.

\section{Plant Growth and Reflectance Data Collection}

We measured reflectance of flower buds and developing fruits (i.e., spikes just before stigma emergence on the lowest flowers and spikes after anthers had dropped off the uppermost flowers, respectively) on a sample of genotypes grown at two temperatures. Genotypes came from 29 European populations. In 2000, Plantago lanceolata L. seeds were collected by maternal family from each population. Populations spanned a latitudinal range of $39^{\circ}-$ $61^{\circ} \mathrm{N}$ and an altitudinal range of $0-1,886 \mathrm{~m}$ (table 1 ). To reduce possible environmentally induced parental effects, we grew one offspring from each of six to 25 maternal families per population in similar conditions for one generation. Most populations included 20-25 maternal families. Offspring grew vegetatively and began flowering naturally in a greenhouse. When flowering began, populations were isolated in growth chambers and greenhouse rooms set at $22^{\circ} \mathrm{C}, 16$-h day $/ 17^{\circ} \mathrm{C}, 8$-h night to allow for random within-population wind pollination. The species is an obligate outcrosser and primarily wind pollinated. After pollination, all populations were moved to growth chambers to mature seeds at the same conditions. By controlling postzygotic temperature (i.e., during flowering and seed maturation), we largely reduced parental temperature effects (Lacey 1996; Lacey and Herr 2000).

We then grew two second-generation maternal half-sibs from five to 17 families per population (table 1). Initially, plants were grown in growth chambers set at $20^{\circ} \mathrm{C}, 10$-h day $/ 15^{\circ} \mathrm{C}$, 14 -h night. After 10 weeks, we divided each plant (genotype) into two genetically identical clones. One clone was randomly assigned to a location in one of three "cool-temperature" chambers. The other was randomly assigned to one of three "warm-temperature" chambers. Half-sibs receiving the same temperature were placed in different chambers. All chambers were kept at $20^{\circ} \mathrm{C}, 16-$ $\mathrm{h}$ day $/ 15^{\circ} \mathrm{C}, 8$-h night for 3 weeks to promote vegetative growth. Then temperatures were reduced to $15^{\circ} \mathrm{C}$ day $/ 10^{\circ} \mathrm{C}$ night or increased to $27^{\circ} \mathrm{C}$ day $20^{\circ} \mathrm{C}$ night for the cooland warm-temperature treatments, respectively. Plants are commonly exposed to these temperatures during reproduction (e.g., fig. 2). Other environmental factors were held as constant as possible. Plants were watered and fertilized with half-strength Hoagland's solution once a day. Light levels ranged from 698 to $713 \mu \mathrm{mol} \mathrm{m}^{-2} \mathrm{~s}^{-1}$ in cool chambers and from 704 to $780 \mu \mathrm{mol} \mathrm{m} \mathrm{m}^{-2} \mathrm{~s}^{-1}$ in warm chambers.

For each plant, we collected a spike just before its onset 
Table 1: Source population characteristics: country of origin, location within country, population symbol, maternal families and genotypes measured (flower buds/developing fruits)

\begin{tabular}{|c|c|c|c|c|c|c|c|}
\hline $\begin{array}{l}\text { Source country, } \\
\text { location in country }\end{array}$ & Symbol & $\begin{array}{l}\text { Latitude } \\
\qquad\left({ }^{\circ} \mathrm{N}\right)\end{array}$ & $\begin{array}{l}\text { Longitude } \\
\quad\left({ }^{\circ} \mathrm{E}\right)\end{array}$ & $\begin{array}{l}\text { Altitude } \\
\qquad(\mathrm{m})\end{array}$ & $\begin{array}{c}\text { Distance } \\
\text { to coast } \\
(\mathrm{km})\end{array}$ & $\begin{array}{c}\text { No. families } \\
\text { flower } \\
\text { (fruit) }\end{array}$ & $\begin{array}{l}\text { No. genotypes } \\
\text { flower } \\
\text { (fruit) }\end{array}$ \\
\hline \multicolumn{8}{|l|}{ Denmark: } \\
\hline Veno & $\mathrm{D}-\mathrm{V}$ & 56.55 & 8.63 & 0 & 0 & $16(\ldots)$ & $32(\ldots)$ \\
\hline \multicolumn{8}{|l|}{ Finland: } \\
\hline Lappi & $\mathrm{F}-\mathrm{L}^{\mathrm{a}}$ & 61.1 & 21.83 & 10 & 13 & $10(10)$ & $20(18)$ \\
\hline \multicolumn{8}{|l|}{ France: } \\
\hline Massif de la Chartreuse & FR-G & 45.37 & 5.4 & 1,000 & 216 & $16(16)$ & $30(28)$ \\
\hline Hameau de St. Felix & FR- $H^{a}$ & 43.58 & 3.97 & 35 & 10 & $16(15)$ & $32(29)$ \\
\hline St. Pierre, Ile d'Oléron & FR-I & 45.95 & -1.29 & 10 & 0 & $14(14)$ & $28(19)$ \\
\hline St. Martin d'Hère & FR-M & 45.17 & 5.77 & 230 & 215 & $17(17)$ & $33(31)$ \\
\hline St. Martin d'Uriage & FR-MU & 45.15 & 5.83 & 684 & 214 & $10(10)$ & $20(18)$ \\
\hline Orsay & FR-O & 48.68 & 2.18 & 80 & 188 & $13(12)$ & $24(23)$ \\
\hline Perros Guirec & FR-P & 48.81 & -3.44 & 15 & 0 & $16(16)$ & $32(30)$ \\
\hline L'Alpe d'Huez & FR-R & 45.09 & 6.07 & 1,886 & 213 & $16(16)$ & $32(29)$ \\
\hline \multicolumn{8}{|l|}{ Germany: } \\
\hline Jena & G-J $J^{a}$ & 50.93 & 11.58 & 150 & 205 & $16(13)$ & $32(26)$ \\
\hline Marburg & G-M & 50.82 & 8.77 & 198 & 191 & $16(\ldots)$ & $29(\ldots)$ \\
\hline Lake Ploen & $\mathrm{G}-\mathrm{P}^{\mathrm{a}}$ & 54.32 & 10.12 & 20 & 27 & $15(15)$ & $30(26)$ \\
\hline \multicolumn{8}{|l|}{ Hungary: } \\
\hline Budapest & H-B & 47.5 & 19.08 & 103 & 426 & $16(\ldots)$ & $28(\ldots)$ \\
\hline \multicolumn{8}{|l|}{ Italy: } \\
\hline Aprilia & I-A & 41.6 & 12.65 & 70 & 10 & $10(9)$ & $20(18)$ \\
\hline Bagni di Vinadio & $\mathrm{I}-\mathrm{B}$ & 44.3 & 7.08 & 1,300 & 67 & $14(14)$ & $28(28)$ \\
\hline Castel Volturno & $\mathrm{I}-\mathrm{CA}^{\mathrm{a}}$ & 41.03 & 13.93 & 1 & 2 & $16(16)$ & $32(30)$ \\
\hline Cosenza & I-CS & 39.3 & 16.25 & 238 & 18 & $5(\ldots)$ & $10(\ldots)$ \\
\hline \multicolumn{8}{|l|}{ Netherlands: } \\
\hline Wassenaar & $\mathrm{N}-\mathrm{W}$ & 52.15 & 4.4 & 20 & 0 & $16(12)$ & $31(25)$ \\
\hline \multicolumn{8}{|l|}{ Romania: } \\
\hline Târgu-Mures & $\mathrm{R}-\mathrm{T}$ & 46.55 & 24.56 & 332 & 440 & $15(15)$ & $28(27)$ \\
\hline \multicolumn{8}{|l|}{ Spain: } \\
\hline Cangoria & SP-C & 42.69 & -.52 & 1,080 & 196 & $16(16)$ & $32(32)$ \\
\hline Orbil de Villanua & $\mathrm{SP}-\mathrm{O}$ & 42.66 & -.54 & 920 & 196 & $16(16)$ & $32(30)$ \\
\hline \multicolumn{8}{|l|}{ Sweden: } \\
\hline Lund & S-L & 55.7 & 13.18 & 47 & 10 & $14(11)$ & $26(17)$ \\
\hline Uppsala & S-U & 59.94 & 17.39 & 20 & 63 & $16(\ldots)$ & $30(\ldots)$ \\
\hline \multicolumn{8}{|l|}{ Switzerland: } \\
\hline Zurich & SW-Z & 47.38 & 8.54 & 434 & 320 & $16(\ldots)$ & $31(\ldots)$ \\
\hline \multicolumn{8}{|l|}{ United Kingdom: } \\
\hline Silwood Park, England & E-S & 51.41 & -.64 & 76 & 46 & $14(\ldots)$ & $27(\ldots)$ \\
\hline Cupar, Scotland & SC-C & 56.32 & -3.01 & 30 & 10 & $11(\ldots)$ & $22(\ldots)$ \\
\hline St. Andrews, Scotland & SC-ST & 56.34 & -2.79 & 30 & 0 & $16(16)$ & $32(29)$ \\
\hline St. David, Pembrokeshire, Wales & W-D & 51.88 & -5.27 & 30 & 14 & $8(7)$ & $15(13)$ \\
\hline
\end{tabular}

Note: Data for developing fruits were collected for 21 populations. See "Methods" for further explanation.

${ }^{a}$ Populations used to test for chamber effect on fruiting data.

of flowering and twice measured percent reflectance from 362 to $850 \mathrm{~nm}$ using a spectrometer with an integrating sphere (for methodology, see Lacey and Herr 2005). The average of the two spectral scans was used for data analysis. We measured fruiting spike reflectance 1 year later on genotypes from 21 populations. Plants were maintained in a greenhouse until then. Flowering was induced in two available growth chambers, one each set at the same warmor cool-temperature conditions. Anthers had withered and fruits were enlarging when spikes were scanned. Because only one chamber was used for each fruiting temperature treatment, we subsequently tested for a possible chamber effect by measuring fruiting reflectance for a sample of five populations (table 1) at cool temperature in both 
chambers. The small chamber effect did not alter the qualitative results or conclusions drawn from the full analyses (E. P. Lacey, unpublished data).

\section{Estimation of Temperature Parameters and Seasonal Temperature Variation during a Reproductive Season}

Temperature parameters were determined from climate data extracted from the Climatic Research Unit Global Climate data set, available at the Data Distribution Centre of the Intergovernmental Panel on Climate Change (http://www.ipcc-data.org). We used 30-year averages (1961-1990) of monthly means for three variables: mean daily temperature and minimum and maximum daily temperatures. The climate data are gridded with $0.5^{\circ}$ resolution for both latitude and longitude. We estimated values for our populations' sites (app. A in the online edition of the American Naturalist) by interpolation, using the values for each site's nearest neighbors. For all but five of the populations, data were available for all four nearest grid points. For three populations (FR-I, I-CA, and I-A; see table 1 for abbreviations), data were available for three nearest neighbors, while for two populations (W-D and FR-P), data were available for two nearest neighbors. In these cases, data were unavailable because one or two neighbors lay over water rather than land. The estimated mean temperature for the whole reproductive season ranged from $12.2^{\circ}$ to $18.6^{\circ} \mathrm{C}$ across the sample populations. Seasonal temperature ranges varied from $6.8^{\circ}$ to $23^{\circ} \mathrm{C}$.

Reproductive duration was estimated from flowering phenology data (e.g., fig. 2) obtained from published guides to local flora (Davies and Gibbons 1993; Fitter et al. 1996; Godet 2002) and from personal observation (E. P. Lacey) and personal communication with biologists who collected seeds for the study (see "Acknowledgments"). Duration ranged from 3 to 8 months. Fruiting phenology data were not available, but fruit maturation likely extended into the month following the last month of flowering.

T-sensitive "degree months" served as our proxy for Tsensitive degree days, for which data were not available. We first fitted a curve to the mean monthly temperatures for each population's site. For the 23 populations whose growing season spanned at least 4 months, we used a thirddegree polynomial. For the six populations whose growing season included only June, July, and August, we used a second-degree polynomial. Using numerical integration, we computed the area under this curve and above the baseline temperature of $5^{\circ} \mathrm{C}$, which was chosen to be slightly lower than the lowest 30-year average of mean monthly minimum temperatures over all of our sample sites. Whole-tissue respiration is very low (see CoveyCrump et al. 2002) at that temperature. The left and right integration bounds (minimum and maximum time-ofyear values) were taken as one-half-month before (after) the first (last) month of the growing season. The area thus computed represents the total degree months for the population. The T-sensitive degree months for the population is the portion of that area below the threshold temperature of $15^{\circ} \mathrm{C}$. Values for T-sensitive degree months ranged from $68 \%$ to $100 \%$ across sample populations.

\section{Statistical Analyses}

All statistical analyses were performed using SAS, version 9.1. Separately for flower buds and developing fruits, we looked at the variation in four dependent variables as a function of latitude, altitude, and distance to the coast. The variables, examined separately, were percent reflectance at warm temperature, percent reflectance at cool temperature, absolute plasticity (the magnitude of change $=$ percent reflectance of the warm-temperature clone minus percent reflectance of the cool-temperature clone of the same genotype) and relative plasticity (=absolute plasticity divided by mean reflectance of the two temperature treatments). Plasticities were calculated for each genotype before analysis. Within the spectral range of 200-850 nm, floral reflectance is most temperature sensitive in the visible region around $550 \mathrm{~nm}$ and in the NIR region (Lacey and Herr 2005; also see Umbach et al. 2009 supplemental fig. 1). The mechanisms underlying thermal sensitivity in these two regions likely differ (Stiles et al. 2007). Therefore, we examined the geographic variation in these four variables at both 550 and $850 \mathrm{~nm}$. Because analyses for absolute plasticity and relative plasticity yielded similar results, we present results only for absolute plasticity and hereafter refer to it as plasticity. We chose not to use the reaction norm slope as a plasticity measure because the difference in day temperatures for our temperature treatments did not equal the difference in night temperatures. Also, because we measured reflectance at only two temperatures, it is unknown whether the relationship between our sample temperatures and reflectance is linear or curvilinear.

Each dependent variable was independently regressed on three geographic variables: latitude, altitude, and distance to the coast. We used multilevel regression models (PROC MIXED) instead of standard regression because genotypic data were clustered by population. Multilevel regression accounts for this hierarchical data structure. The multilevel model fits regression models on two levels, genotype and population. The slope and intercept at the genotype level depend on the population-level variables, and in this way, within-population variation can be incorporated into the analysis to avoid overstating the strength of relationships at the population level (Singer 
1998; Raudenbush and Bryk 2002). To determine the bestfitting model to our data, we fitted both linear and quadratic models. To help reduce multicollinearity between the linear and quadratic latitude/altitude terms in the quadratic models, we mean-corrected latitude/altitude by subtracting the mean of the respective variable before running each analysis. On the basis of the Akaike Information Criterion fit statistic, a linear model provided a good fit for each dependent variable and was used for all analyses.

PCA of our temperature parameters was used to produce composite measures of, that is, proxies for, the thermal environment. Parameters were mean (average of 30year mean monthly temperatures for months in the reproductive season), duration (number of months in the reproductive season), range (highest 30-year mean monthly maximum temperature - lowest 30-year mean monthly minimum temperature for the months in the reproductive season), T-sensitive temperature range $\left(15^{\circ} \mathrm{C}\right.$ - lowest 30 -year mean monthly minimum temperature for months in the reproductive season), and Tsensitive degree months (percent of total degree months in the T-sensitive fitness zone). Because these parameters were not commensurate and had variances that differed substantially, PCA was performed on the standardized variables (i.e., on the correlation matrix).

Using PCA axes PC1 and PC2 as proxies for the thermal environment, we then used structural equation modeling to perform path analyses of the data (e.g., Mitchell 1992; Petraitis et al. 1996; Grace and Pugesek 1998; Scheiner et al. 2000). Given an a priori path model that defines the predictive relationships between multiple dependent variables, path analysis measures the strength of the relationships (Wright 1934; Li 1975). It also tests models for goodness of fit. We report the $X^{2}$ value (significant value = lack of fit to the data) and Bentler's and Bonett's normed fit index (NFI), which is based on the model $X^{2}$ relative to that of a model that assumes independence of all variables. NFI ranges between 0 and 1 , with NFI $>0.90$ indicating a good fit (Bentler 1989). The NFI procedure assumes no particular distribution for the variables in a model.

We analyzed path models (PROC CALIS) for plasticities at 550 and $850 \mathrm{~nm}$ at both flower bud $(N=29$ populations) and fruiting $(N=21)$ stages. Each model included latitude, altitude, and distance to the coast, which could affect PC1, PC2, and mean reflectance plasticity per population (fig. 3). Also, PC1 and PC2 could affect plasticity. For each direct path between two variables, we calculated the path coefficient (standardized slope of the regression between two variables). A path coefficient measures the direct predictive effect of one variable on another, such as, effect of latitude on PC1. The significance of each path coefficient was evaluated using a $t$-test. Ab- solute values of $t>2$ were considered statistically significant. Path coefficients are also used to measure the indirect effect between two traits as mediated by one or more other variables. For example, the indirect effect of latitude on plasticity via PC1 is the product of the path coefficients from latitude to PC1 and from PC1 to plasticity.

Last, we examined the relationships between plasticity and the five temperature parameters. We regressed plasticity on PC1, which allowed us to examine the relationships using standardized temperature parameters that contributed most to PC1. We performed multilevel regressions (PROC MIXED) on the raw data for each temperature parameter to determine whether the relationships were biologically meaningful. Using all temperature parameters simultaneously, we performed standard regressions to determine which combination of parameters best predicted mean plasticity of a population.

\section{Results}

Reflectance/color plasticity of flower buds and developing fruits was positively and significantly correlated with latitude (fig. 4; app. B in the online edition of the American Naturalist). Response to cool temperature rather than to warm temperature explained this clinal variation (fig. 4; app. B). Only at cool temperature did bud/fruit reflectance at both wavelengths decline substantially with increasing latitude (e.g., fig. $4 B, 4 D$ ). For lowland populations alone, NIR $(850 \mathrm{~nm})$ bud reflectance declined approximately $20 \%$ from $40^{\circ}$ to $60^{\circ} \mathrm{N}$ (fig. $4 B$, trendline). For maritime populations alone, visible (550 $\mathrm{nm}$ ) bud reflectance declined more than $30 \%$ over the same range (fig. $4 D$, trendline). Altitudinal patterns resembled the latitudinal patterns (fig. 4A, 4B). Cool-temperature reflectance and, thus, plasticity declined and increased, respectively, with increasing altitude, and clines were statistically significant for developing fruits (app. B). We also detected a statistically significant decline in visible bud reflectance at cool temperature with increasing distance from the coast (fig. 4D; app. B).

PCA showed that the first two composite indexes, PC1 and PC2, explained 58\% and 37\%, respectively (jointly = $95 \%$ total), of the thermal-environment variation across sample populations. Duration of the reproductive season, seasonal temperature range, and seasonal T-sensitive degree months contributed substantially and approximately equally to PC1 (duration, seasonal range, and T-sensitive degree months loadings $=0.49,0.55$, and -0.51 , respectively, in contrast to mean and T-sensitive range loadings $=0.39$ and 0.21 , respectively). T-sensitive range and the mean contributed most to PC2 (T-sensitive range, mean, T-sensitive degree months, duration, and seasonal tem- 


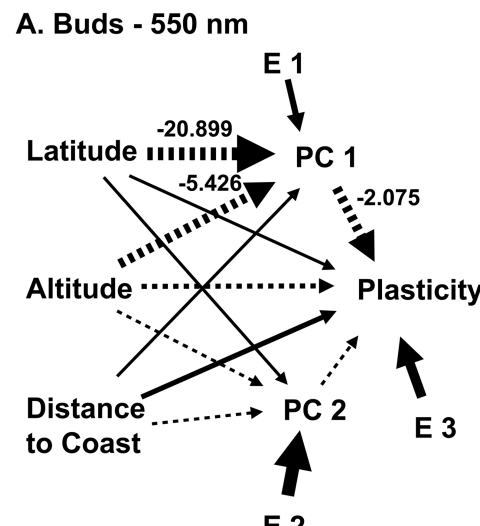

\section{Fruits $-550 \mathrm{~nm}$}

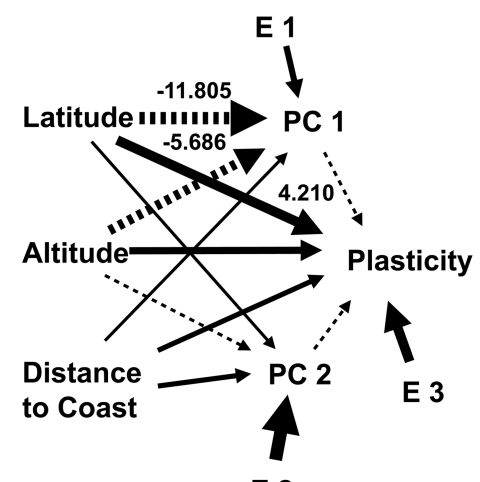

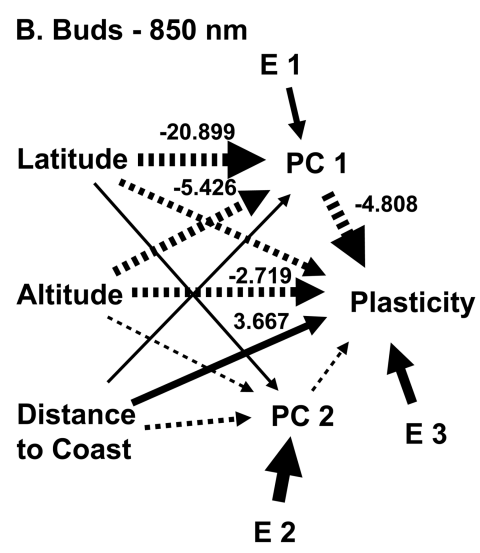

D. Fruits - $850 \mathrm{~nm}$

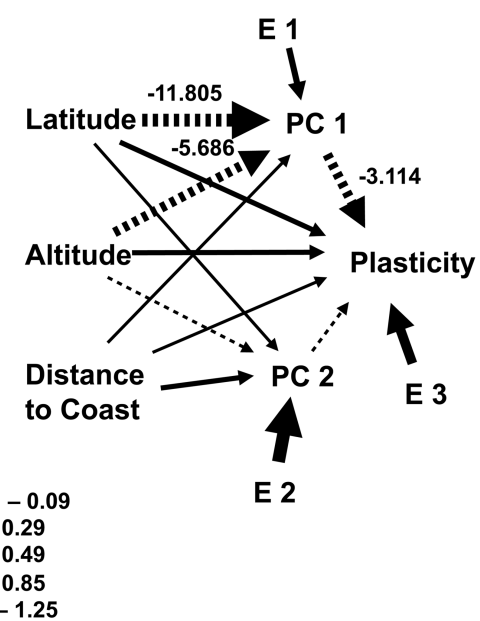

Figure 3: Path models showing direct and indirect effects, as mediated by the thermal environment (PC1 and PC2), of latitude, altitude, and distance to the coast on reflectance plasticity at 550 and $850 \mathrm{~nm}$ in Plantago lanceolata. $A, B$, Flower buds; $C$, $D$, developing fruits. Coefficient strength indicated by arrow width. Solid line, positive effect; dashed line, negative effect. Values for temperature are shown for statistically significant paths. Appendix $\mathrm{C}$ in the online edition of the American Naturalist has path coefficients and indirect effects for all models and describes E1-E3.

perature range loadings $=0.67,-0.55,0.35,0.29$, and 0.19 , respectively).

Path models showed a good fit with the data (for all models: $\chi^{2}$ test, $P>.74$; NFI $=1.0$ ) and showed strong predictive effects of latitude and altitude but not coastal distance on reflectance plasticity (fig. 3; app. C in the online edition of the American Naturalist). Absolute values for direct effects ranged from 0.001 to 1.125 . Statistically significant path coefficients were associated with the indirect effects of latitude and altitude on plasticity via PC1 in three of four models (fig. $3 A, 3 B, 3 D$ ). The path coefficient for the direct path from latitude to plasticity was statistically significant in one model (fig. 3C); coefficients for direct paths from coastal distance and altitude to plasticity were statistically significant for one model (fig. 3B).
For three models, the indirect effects via PC1 contributed substantially more to the total predictive effects of latitude and altitude on plasticity than did the direct effects (fig. 3; values in app. C). Path coefficients involving PC2 were never statistically significant.

PC1 loadings (given above) showed positive correlations between PC1 and duration of reproductive season, temperature range, and mean seasonal temperature. $\mathrm{PC} 1$ and T-sensitive degree months were negatively correlated. Also, reflectance plasticity and PC1 were negatively correlated (app. D in the online edition of the American Naturalist). Therefore, plasticity declined with increasing duration, range, and mean temperature but increased with increasing T-sensitive degree months.

The multilevel regressions showed statistically signifi- 
A)

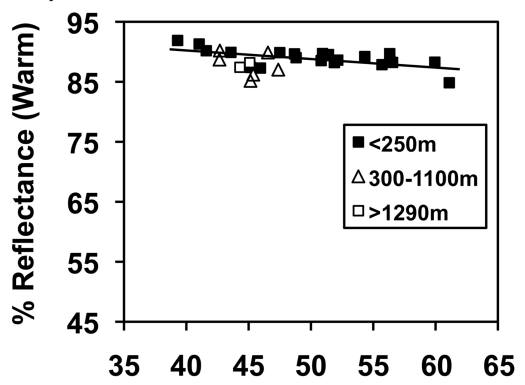

B)

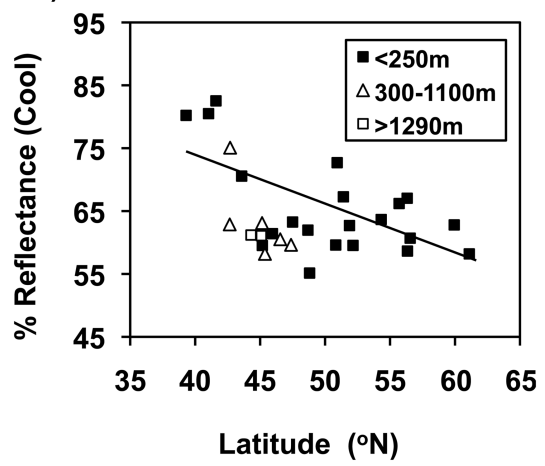

C)

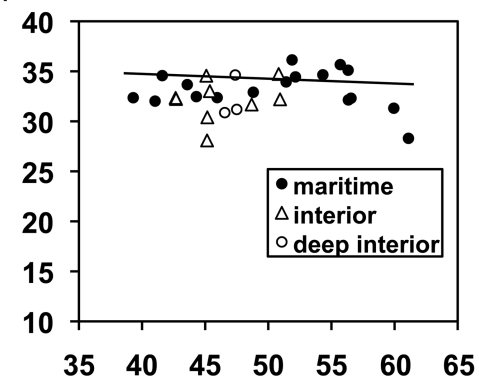

D)

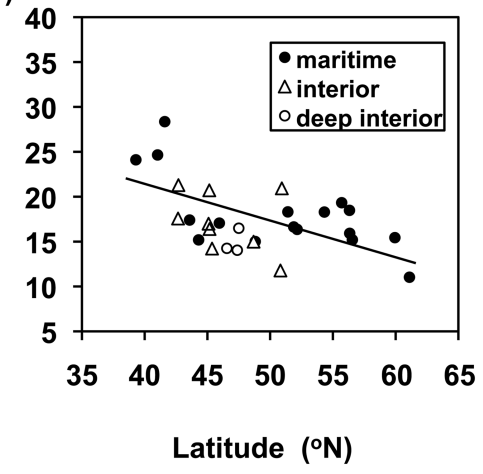

Figure 4: Latitudinal and altitudinal variation in flower bud reflectance: $850 \mathrm{~nm}$ at warm temperature $(A), 850 \mathrm{~nm}$ at cool temperature $(B), 550$ $\mathrm{nm}$ at warm temperature $(C)$, and $550 \mathrm{~nm}$ at cool temperature $(D)$. Altitude: $<250,300-1,100,>1,290 \mathrm{~m}$ above sea level. Maritime $=<70 \mathrm{~km}$, interior $=180-220 \mathrm{~km}$, deep interior $=>300 \mathrm{~km}$ from the nearest coast. Trendlines in $A$ and $B$ are for maritime populations. Trendlines in $C$ and $D$ are for populations $<255 \mathrm{~m}$ above sea level. Regression coefficients are given in appendix B in the online edition of the American Naturalist.

cant and biologically meaningful relationships between plasticity and duration, range, and T-sensitive degree months (fig. 5). For example, NIR bud plasticity declined approximately $50 \%$ from populations experiencing the least to those experiencing the most temperature variation during the reproductive season (fig. $5 \mathrm{~A}$ ). Plasticity declined approximately $30 \%$ as flowering season increased from 3 to 8 months (fig. $5 B$ ). It increased about $60 \%$ as T-sensitive degree months increased from approximately $70 \%$ to $100 \%$ (fig. 5C). In contrast, bud plasticity was weakly associated with mean temperature (fig. $5 D$ ) and T-sensitive range (fig. 5I). Plasticity of developing fruits showed similar patterns (fig. $5 F-5 J$ ), except that plasticity declined significantly as mean temperature increased (fig. 5I). Because of the strong correlations among temperature parameters, multiple combinations of parameters predicted plasticity equally well (e.g., app. E in the online edition of the American Naturalist). There was no "one best" combination.

\section{Discussion}

In the nineteenth century, naturalists reported that in some species, flower color intensity increased with increasing latitude and altitude (Bonnier and Flahault 1878a, 1878b; Flahault 1878; Pellat 1878; von Marilaun Kerner and Oliver 1894). As far as we can determine, our study is the first to quantify this variation experimentally and test hypotheses about its origin. Although not noted by the naturalists, Plantago lanceolata shows parallel latitudinal and altitudinal clines in T-sensitive plasticity in floral reflectance in the visible and NIR regions. Plasticity increases northward and with increasing altitude. Also, cooltemperature reflectance visibly declines (i.e., color darkens) toward the continental interior. Had we sampled more populations along the continental gradient, we might have detected a statistically significant cline also for plasticity.

This clinal variation is best explained by genetic divergence due to adaptation to the local thermal environment. Taking our experimental populations through one generation under similar environmental conditions before our experiment reduced parental effects arising from differences in temperature, photoperiod, and resource availability among the natural population sites. Thus, the observed population differences in reflectance plasticity likely reflect genetic differences. Also, because the species is an obligate outcrosser, our experimental genotypes probably 
A)

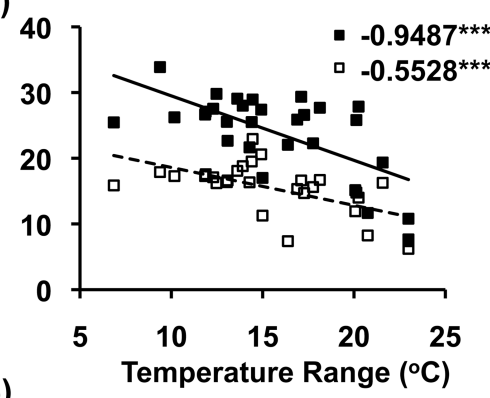

B)

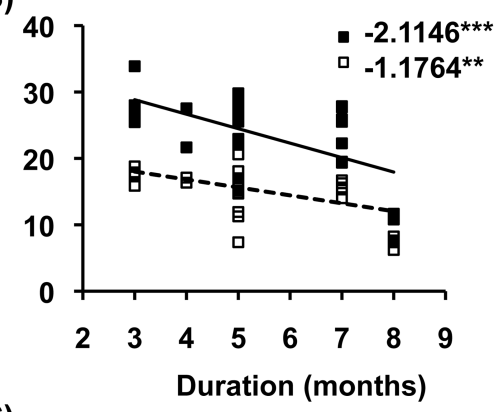

C)

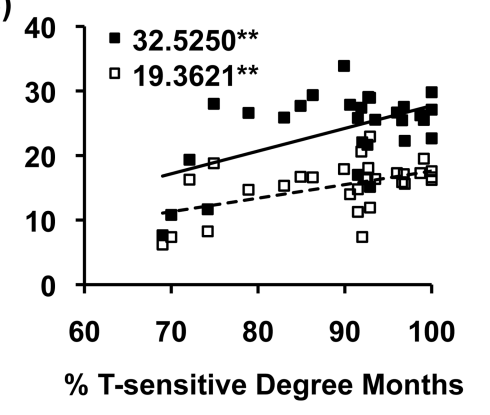

D)

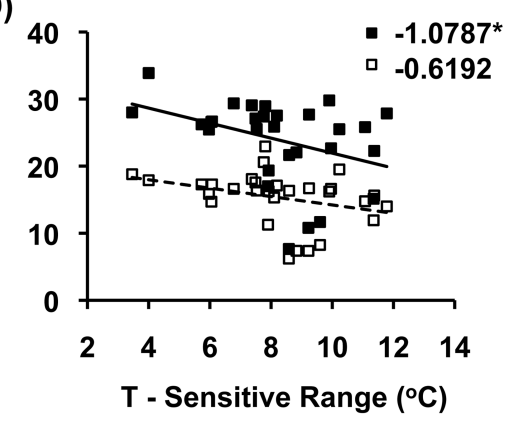

E)

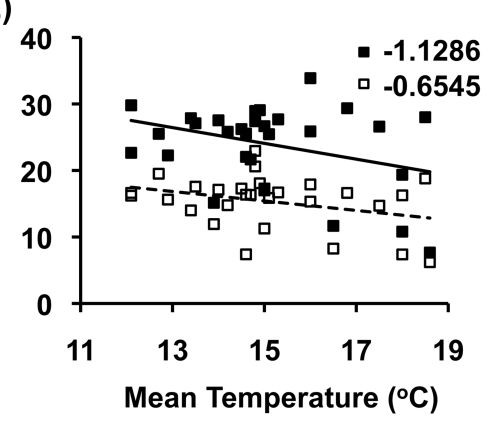

F)

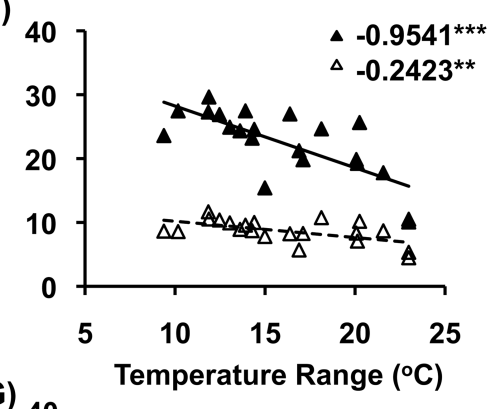

G)

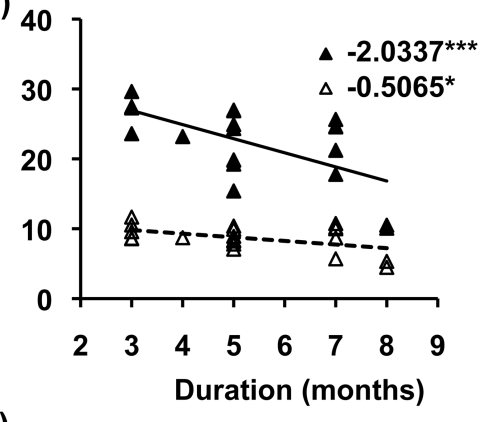

H)

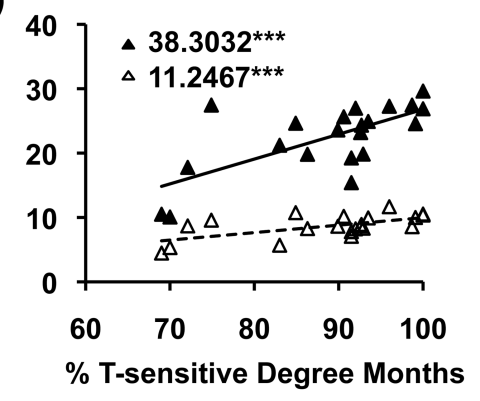

I)

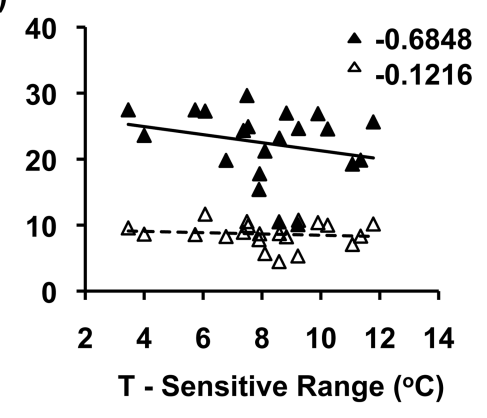

J)

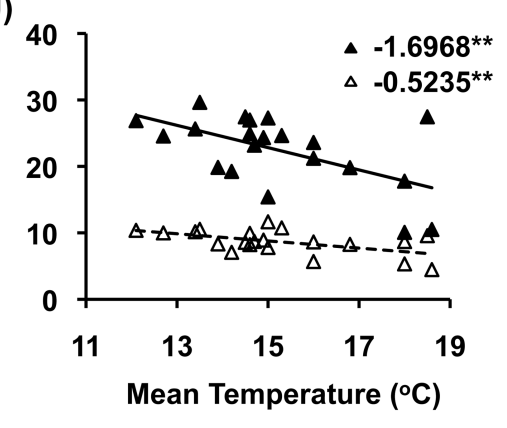


reasonably sampled within-population genetic variation. Third, path analyses provide evidence that latitude and altitude influence plasticity indirectly via the thermal environment. Natural selection has probably played a stronger role in producing the geographic patterns than have other evolutionary forces. Multiple populations sampled at each geographic margin resembled each other in degree of plasticity, suggesting that they are under similar selection pressures. Also, the altitudinal pattern paralleled the latitudinal pattern. Had other evolutionary forces, for example, genetic drift or mutation, played stronger roles than natural selection, we would not expect to see these similarities.

Previous geographic studies of thermal acclimation have generally compared acclimation ability between species found along latitudinal/altitudinal gradients (AddoBediako et al. 2000; Howe et al. 2003; Ghalambor et al. 2006). Interspecific variation is presumed to have arisen initially from genetic divergence of populations within species. If so, then parallel latitudinal/altitudinal patterns should also be detectable within widely distributed species. Our data provide evidence for this in a plant species and parallel geographic patterns recently detected within dung beetle and mosquito species (Gaston and Chown 1999; Ragland and Kingsolver 2008).

Consistent with some insects (Gaston and Chown 1999; Addo-Bediako et al. 2000; Ragland and Kingsolver 2008), $P$. lanceolata populations vary only in response to cool temperatures. More northerly and higher-altitude populations showed greater capacity to reduce reflectance (darken flowers) at cool temperature and thereby absorb more solar radiation, which would warm gametes, gametophytes, and embryonic offspring during cool periods of the reproductive season. Warm temperatures during reproduction have been shown experimentally to improve offspring fitness (Lacey and Herr 2000).

We did not observe that floral reflectance plasticity is highest at midlatitudes and lowest at the extremes, as we thought we might. Nonplastic, highly reflective genotypes were more common in the southernmost populations; however, nonplastic, poorly reflective genotypes were absent in the northernmost populations. Two reasons likely explain this. First, cool reproductive periods would not be able to select for nonplastic, poorly reflective genotypes because they phenotypically resemble plastic phenotypes at cool temperatures. Second, even in the coolest popu- lations, maximum daily temperatures in the warmest months rise above $15^{\circ} \mathrm{C}$ (e.g., see fig. 2). Therefore, if reducing reflectance is costly, not reducing reflectance during the warmest reproductive period may result in a net fitness gain. Available evidence suggests that there is an energetic cost associated with reducing reflectance in the visible portion of the spectrum because of increased anthocyanin content at low temperatures (Stiles et al. 2007).

Although the latitudinal and altitudinal patterns of floral reflectance plasticity parallel patterns detected in studies of thermal acclimation in other organisms, our results do not support the explanation that the patterns have arisen because of greater temperature variation at higher latitude and altitude (TVH). Plasticity and temperature range were strongly correlated, but reflectance plasticity decreased as temperature range increased. The patterns are better explained by geographic variation in the relative amount of time spent reproducing at temperatures for which there should be a large fitness benefit from thermoregulation (VSIH). Plasticity increased significantly with increasing T-sensitive degree months (i.e., proportion of time exposed to temperatures $<15^{\circ} \mathrm{C}$ ) and, thus, also declining mean seasonal temperature. Concomitantly, it declined with increasing duration of the reproductive season. If we expand our model of the thermal environment during the reproductive season (as shown in fig. 1) across latitudinal or altitudinal gradients, we can visualize how duration and time spent in the T-sensitive zone could jointly explain geographic patterns of plasticity in thermoregulatory traits. For example, at high latitudes, mean monthly temperatures during the reproductive season lie in the T-sensitive zone, where, by definition, a small increase in body temperature, that is, thermoregulation, should produce a relatively large fitness benefit (fig. 6). However, as latitude declines, seasonal temperatures rise further and further above the threshold temperature, and length and proportion of time in the T-insensitive zone increase. Thus, more reproductive time is spent at temperatures where the fitness benefit of thermoregulation is low or negligible, and the probability of completing flowering and fruiting entirely in the T-insensitive zone increases. Consequently, the selection intensity favoring plasticity declines.

Previous evolutionary studies of phenotypic plasticity have commonly examined the correlations between plasticity and environmental parameters that are physiologically independent of the organism under study (e.g., yearly

Figure 5: Relationships (with slope estimates) for flower bud plasticity and total temperature range $(A)$, duration of reproductive season (B), temperature $(\mathrm{T})$-sensitive degree months $(C)$, T-sensitive temperature range $(D)$, mean seasonal temperature $(E)$, and for plasticity of developing fruits and total temperature range $(F)$, duration of reproductive season $(G)$, T-sensitive degree months $(H)$, T-sensitive temperature range $(I)$, and mean seasonal temperature $(J)$. Filled symbols, solid line, $850 \mathrm{~nm}$; open symbols, dashed line, $550 \mathrm{~nm}$. One asterisk, $P<.05 ;$ two asterisks, $P<.01 ;$ three asterisks, $P<.001$. 


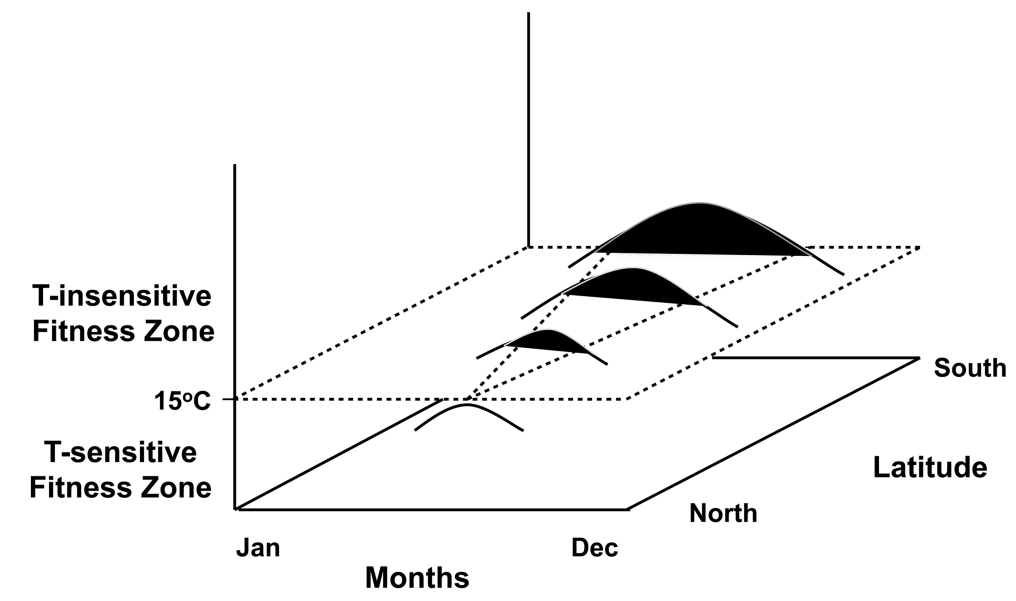

Figure 6: Conceptual model of seasonal temperature variation shown in figure 1 as applied to sample populations and extended across a latitudinal gradient. See figure 1 and "Discussion" for additional information.

mean or range). A limitation of using such parameters is that they provide minimal information about the mechanism(s) linking environmental variability to the evolution of plasticity. They might even be misleading. For example, plasticity shows no significant relationship with annual temperature range for $P$. lanceolata (app. F in the online edition of the American Naturalist). Ideally, we would like to understand the "mechanistic cascade" (Angilletta et al. 2006), the mechanistic links between environmental variation and the functional responses at different levels of biological organization, as well as the fitness effects (Pigliucci 1996; Angilletta et al. 2006; Visser 2008). For this reason, we restricted calculations of our temperature parameters to the reproductive months. This restriction helps us to understand better why correlations between plasticity and physiologically independent parameters do or do not exist and, for P. lanceolata, why plasticity is not positively correlated with seasonal thermal variation. Restricting geographic studies of thermoregulation to time periods of organismal activity, for example, excluding periods of diapause or dormancy, may help us better understand the evolution of thermoregulation in ectotherms, generally.

We assumed in our study that the threshold temperature dividing T-sensitive and T-insensitive fitness zones was constant for all populations and that the threshold temperature for roots applied to reproductive structures. We also estimated the threshold temperature using information about temperature's effect on respiration rate. Respiration rate in reproductive tissues is likely to strongly influence seed production and quality. However, respiration rate is generally measured in vegetative, not reproductive, tissues (Umbach et al. 2009). Also, studies examining temperature's influence on respiration relative to other factors over a range of growth temperatures, even in vegetative structures, are negligible. Covey-Crump et al. (2002) did observe that $15^{\circ} \mathrm{C}$ serves as a reasonable threshold temperature for Plantago euryphylla roots, as well as for $P$. lanceolata. Thus, although respiration response curves likely differ along latitudinal and altitudinal gradients, it is currently unknown how they differ.

Thus far, we have focused our attention on the benefits of thermoregulation rather than the costs. Costs may constrain the evolution of plasticity by offsetting benefits (Huey and Slatkin 1976; Schlichting 1986; Sultan 1987; van Tienderen 1991; DeWitt et al. 1998; Scheiner and Berrigan 1998; Johansson 2002; Stinchcombe et al. 2003; Callahan et al. 2005; Weinig et al. 2006; Valladares et al. 2007), although there are counterexamples (e.g., van Kleunen and Fischer 2005; Caruso et al. 2006). Huey and Slatkin (1976) proposed that thermoregulation would be favored over thermoconformity when costs of thermoregulation were low relative to the benefits. Our data are consistent with this prediction. However, their model assumed that the cost of thermoregulation increases the further ambient temperature deviates from an optimal body temperature, while the benefit of thermoregulation remains constant. If these assumptions were applied to plasticity in P. lanceolata, we would predict that floral reflectance plasticity should decline poleward and with increasing altitude, which is opposite to our observed results. More likely, the benefit of even partial thermoregulation increases as ambient temperature deviates further from the optimal temperature range, and the benefit increases more strongly than any possible increase in cost. This explanation is consistent with thermoregulatory behavior in high-latitude, ectothermic animals (Herczeg et al. 2003; Blouin-Demers 
and Nadeau 2005) and may explain large-scale geographic variation in thermoregulatory ability in ectotherms, generally.

The impetus for large-scale geographical studies such as this one has arisen in part because of a need to predict the physiological responses of organisms to global warm ing (Howe et al. 2003; Valladares et al. 2007; Deutsch et al. 2008). This understanding will come through studies of not only thermal tolerance, that is, survival, but also thermal performance, including reproductive performance. Thermal performance curves are generally narrower than tolerance curves (Gilchrist 1995), and evolutionary survival depends on survival and reproduction. Most plant reproductive studies addressing climate change have focused on reproductive timing (e.g., Parmesan et al. 2000; Stinchcombe et al. 2004; Franks et al. 2007; Springer and Ward 2007). Our results highlight the value of examining reproductive responses within a reproductive sea. son. Our data suggest that if global temperatures continue to rise, then the selection pressure favoring thermoregulation at high latitudes and altitudes should wane. Tht $\rightarrow$ frequency and geographic distribution of nonplastic, highly reflective genotypes should increase and spread toward the poles and higher altitudes, respectively. Globaı warming would alter the genetic structure of existing populations with respect to floral reflectance and genetically correlated traits. In this context, our study underscores the need to understand better the physiology of temperaturesensitive reproductive traits.

\section{Acknowledgments}

We thank G. Gilchrist, D. Houle, and J. Kingsolver for helpful comments on previous versions of this article and the following biologists for sending us seeds: R. Abbot, J. Ågren, I. G. Alsos, B. Bengtsson, M. Clauss, S. Cozzolino, G. D’Amato, T. de Jong, L. Garamszegi, M. B. Garcia, B. Giles, D. Matthies, R. Milne, A. Mussachio, P. Pap, A. Ressayre, C. Rueffler, E. Ruprecht, O. Savolainen, J. Shykoff, M. Siuruain, J. Thompson, and S. Yakovlev. We also thank the many undergraduates who helped with plan $\rightarrow$ care and data collection, the National Science Foundation (NSF) for supporting the research (DEB 0236526 to E.P.L.), and the National Evolutionary Synthesis Center (NSF EF-0423641 to the National Evolutionary Synthesis Center) for financial support while E.P.L. wrote tht manuscript.

\section{Literature Cited}

$\rightarrow$ Addo-Bediako, A., S. L. Chown, and K. J. Gaston. 2000. Thermal tolerance, climatic variability and latitude. Proceedings of the Royal Society B: Biological Sciences 267:739-745.

$\rightarrow$ Angilletta, M. J., A. F. Bennett, H. Guderley, C. A. Navas, F. Seebacher, and R. S. Wilson. 2006. Coadaptation: a unifying principle in evolutionary thermal biology. Physiological and Biochemical Zoology 79:282-294.

Arnold, S. J., and C. R. Peterson. 2002. A model for optimal reaction norms: the case of the pregnant garter snake and her temperaturesensitive embryos. American Naturalist 160:306-316.

Atkin, O. K., D. Bruhn, V. M. Hurry, and M. G. Tjoelker. 2005. The hot and the cold: unravelling the variable response of plant respiration to temperature. Functional Plant Biology 32:87-105.

Bentler, P. M. 1989. EQS structural equations program manual. BMDP Statistical Software, Los Angeles.

Blouin-Demers, G., and P. Nadeau. 2005. The cost-benefit model of thermoregulation does not predict lizard thermoregulatory behavior. Ecology 86:560-566.

Bonnier, G., and C. Flahault. 1878a. Observations sur les modifications des végétaux. Annales des Sciences Naturelles Botanique 7:93-125.

- $1878 b$. Sur les variations qui se produisent avec la latitude dans une même espèce végétale. Bulletin de la Société Botanique de France 25:300-306.

Callahan, H. S., N. Dhanoolal, and M. C. Ungerer. 2005. Plasticity genes and plasticity costs: a new approach using an Arabidopsis recombinant inbred population. New Phytologist 166:129-139.

Caruso, C. M., H. Maherali, and M. Sherrard. 2006. Plasticity of physiology in Lobelia: testing for adaptation and constraint. Evolution 60:980-990.

Collinge, J. E., A. A. Hoffmann, and S. W. McKechnie. 2006. Altitudinal patterns for latitudinally varying traits and polymorphic markers in Drosophila melanogaster from eastern Australia. Journal of Evolutionary Biology 19:473-482.

$\rightarrow$ Covey-Crump, E. M., R. G. Attwood, and O. K. Atkin. 2002. Regulation of root respiration in two species of Plantago that differ in relative growth rate: the effect of short- and long-term changes in temperature. Plant Cell and Environment 25:1501-1513.

$\rightarrow$ Cunningham, S. C., and J. Read. 2002. Comparison of temperate and tropical rainforest tree species: photosynthetic responses to growth temperature. Oecologia (Berlin) 133:112-119.

Davies, P., and B. Gibbons. 1993. Field guide to wild flowers of southern Europe. Crowood, Ramsbury.

Deutsch, C. A., J. J. Tewksbury, R. B. Huey, K. S. Sheldon, C. K. Ghalambor, D. C. Haak, and P. R. Martin. 2008. Impacts of climate warming on terrestrial ectotherms across latitude. Proceedings of the National Academy of Sciences of the USA 105:6668-6672.

DeWitt, T., and S. Scheiner. 2004. Phenotypic plasticity: functional and conceptual approaches. Oxford University Press, New York.

DeWitt, T. J., A. Sih, and D. S. Wilson. 1998. Costs and limits of phenotypic plasticity. Trends in Ecology \& Evolution 13:77-81.

Fitter, R., A. Fitter, and M. Blamey. 1996. Wild flowers of Britain and northern Europe. Harper Collins, London.

Flahault, C. 1878. Nouvelles observations sur les modifications des végétaux. Annales des Sciences Naturelles Botanique 9:159-207.

$\rightarrow$ Franks, S. J., S. Sim, and A. E. Weis. 2007. Rapid evolution of flowering time by an annual plant in response to a climate fluctuation. Proceedings of the National Academy of Sciences of the USA 104: 1278-1282.

$\rightarrow$ Gabriel, W., and M. Lynch. 1992. The selective advantage of reaction norms for environmental tolerance. Journal of Evolutionary Biology 5:41-59.

$\rightarrow$ Gaston, K. J., and S. L. Chown. 1999. Elevation and climatic tolerance: a test using dung beetles. Oikos 86:584-590. 
$\rightarrow$ Gavrilets, S., and S. M. Scheiner. 1993a. The genetics of phenotypic plasticity. 5. Evolution of reaction norm shape. Journal of Evolutionary Biology 6:31-48.

$\rightarrow$. 1993b. The genetics of phenotypic plasticity. 6 . Theoretica predictions for directional selection. Journal of Evolutionary Biology 6:49-68.

$\rightarrow$ Ghalambor, C. K., R. B. Huey, P. R. Martin, J. J. Tewksbury, and G. Wang. 2006. Are mountain passes higher in the tropics? Janzen's hypothesis revisited. Integrative and Comparative Biology 46:517.

$\rightarrow$ Gilchrist, G. W. 1995. Specialists and generalists in changing environments. 1. Fitness landscapes of thermal sensitivity. American Naturalist 146:252-270.

Godet, J.-D. 2002. Guide panoramique des fleurs de montagne. Delachaux \& Niestlé, Paris.

$\rightarrow$ Gomulkiewicz, R., and M. Kirkpatrick. 1992. Quantitative genetics and the evolution of reaction norms. Evolution 46:390-411.

$\rightarrow$ Grace, J. B., and B. H. Pugesek. 1998. On the use of path analysis and related procedures for the investigation of ecological problems American Naturalist 152:151-159.

Herczeg, G., T. Kovacs, A. Hettyey, and J. Merila. 2003. To thermoconform or thermoregulate? an assessment of thermoregulatior opportunities for the lizard Zootoca vivipara in the subarctic. Polar Biology 26:486-490.

$\rightarrow$ Howe, G. T., S. N. Aitken, D. B. Neale, K. D. Jermstad, N. C. Wheeler, and T. H. H. Chen. 2003. From genotype to phenotype: unraveling the complexities of cold adaptation in forest trees. Canadian Journal of Botany 81:1247-1266.

$\rightarrow$ Huber, H., N. C. Kane, M. S. Heschel, E. J. von Wettberg, J. Banta, A. M. Leuck, and J. Schmitt. 2004. Frequency and microenvironmental pattern of selection on plastic shade-avoidance traits in : natural population of Impatiens capensis. American Naturalist 163: 548-563.

$\rightarrow$ Huey, R. B., and M. Slatkin. 1976. Cost and benefits of lizard thermoregulation. Quarterly Review of Biology 51:363-384.

$\rightarrow$ Janzen, D. H. 1967. Why mountain passes are higher in the tropics American Naturalist 101:233-249.

$\rightarrow$ Johansson, F. 2002. Reaction norms and production costs of predator-induced morphological defences in a larval dragonfl; (Leucorrhinia dubia: Odonata). Canadian Journal of Zoology 80: 944-950.

Kingsolver, J. G., and R. B. Huey. 1998. Evolutionary analyses of morphological and physiological plasticity in thermally variable environments. American Zoologist 38:545-560.

$\rightarrow$ Kingsolver, J. G., H. E. Hoekstra, J. M. Hoekstra, D. Berrigan, S. N. Vigneri, C. E. Hill, A. Hoang, P. Gibert, and P. Beerli. 2001. Thi strength of phenotypic selection in natural populations. American Naturalist 157:245-261.

$\rightarrow$ Lacey, E. P. 1996. Parental effects in Plantago lanceolata L. I. A growth chamber experiment to examine pre- and post-zygotic temperature effects. Evolution 50:865-878.

$\rightarrow$ Lacey, E. P., and D. Herr. 2000. Parental effects in Plantago lanceolata L. III. Measuring parental temperature effects in the field. Evolution 54:1207-1217.

$\rightarrow-$ 2005. Phenotypic plasticity, parental effects and parental care in plants? I. An examination of spike reflectance in Plantago lanceolata (Plantaginaceae). American Journal of Botany 92:920-930.

$\rightarrow$ Lacey, E. P., D. A. Roach, D. Herr, S. Kincaid, and R. Perrott. 2003. Multigenerational effects of flowering and fruiting phenology in Plantago lanceolata. Ecology 84:2462-2475.
Levins, R. 1968. Evolution in changing environments. Princeton University Press, Princeton, NJ.

Li, C. C. 1975. Path analysis: a primer. Boxwood, Pacific Grove, CA.

Lynch, M., and W. Gabriel. 1987. Environmental tolerance. American Naturalist 129:283-303.

$\rightarrow$ Mitchell, R. J. 1992. Testing evolutionary and ecological hypotheses using path analysis and structural equation modelling. Functional Ecology 6:123-129.

Naya, D. E., F. Bozinovic, and W. H. Karasov. 2008. Latitudinal trends in digestive flexibility: testing the climatic variability hypothesis with data on the intestinal length of rodents. American Naturalist 172:E122-E134.

$\rightarrow$ Parmesan, C., T. L. Root, and M. R. Willig. 2000. Impacts of extreme weather and climate on terrestrial biota. Bulletin of the American Meteorological Society 81:443-450.

Pellat, A. 1878. Sur quelques variations que presentent les végétaux avec l'altitude. Bulletin de la Société Botanique de France 25:307308.

Petraitis, P. S., A. E. Dunham, and P. H. Niewiarowski. 1996. Inferring multiple causality: the limitations of path analysis. Functional Ecology 10:421-431.

Pigliucci, M. 1996. How organisms respond to environmental changes: from phenotypes to molecules (and vice versa). Trends in Ecology \& Evolution 11:168-173.

Ragland, G. J., and J.G. Kingsolver. 2008. Evolution of thermotolerance in seasonal environments: the effects of annual temperature variation and life-history timing in Wyeomyia smithii. Evolution 62:1345-1357.

Raudenbush, S. W., and A. S. Bryk. 2002. Hierarchical linear models. 2nd ed. Sage, Thousand Oaks, CA.

Scheiner, S. M. 1993. Genetics and evolution of phenotypic plasticity. Annual Review of Ecology and Systematics 24:35-68.

$\rightarrow$ Scheiner, S. M., and D. Berrigan. 1998. The genetics of phenotypic plasticity. VIII. The cost of plasticity in Daphnia pulex. Evolution 52:368-378.

Scheiner, S. M., J. Mitchell, and H. S. Callahan. 2000. Using path analysis to measure natural selection. Journal of Evolutionary Biology 13:423-433.

Schlichting, C. D. 1986. The evolution of phenotypic plasticity in plants. Annual Review of Ecology and Systematics 17:667-693.

Schlichting, C. D., and M. Pigliucci. 1998. Phenotypic evolution: a reaction norm perspective. Sinauer, Sunderland, MA.

Singer, J. D. 1998. Using SAS PROC MIXED to fit multilevel models, hierarchical models, and individual growth models. Journal of Educational and Behavioral Statistics 24:323-355.

Springer, C. J., and J. K. Ward. 2007. Flowering time and elevated atmospheric $\mathrm{CO}_{2}$. New Phytologist 176:243-255.

Stiles, E. A., N. B. Cech, S. M. Dee, and E. P. Lacey. 2007. Temperature-sensitive anthocyanin production in flowers of Plantago lanceolata. Physiologia Plantarum 129:756-765.

Stinchcombe, J. R., L. A. Dorn, and J. Schmitt. 2003. Flowering time plasticity in Arabidopsis thaliana: a reanalysis of Westerman \& Lawrence (1970). Journal of Evolutionary Biology 17:197-207.

$\rightarrow$ Stinchcombe, J. R., C. Weinig, M. Ungerer, K. M. Olsen, C. Mays, S. S. Halldorsdottir, M. D. Purugganan, and J. Schmitt. 2004. A latitudinal cline in flowering time in Arabidopsis thaliana modulated by the flowering time gene FRIGIDA. Proceedings of the National Academy of Sciences of the USA 101:4712-4717.

Sultan, S. E. 1987. Evolutionary implications of phenotypic plasticity in plants. Evolutionary Biology 21:127-178. 
$\rightarrow$ Umbach, A. L., E. P. Lacey, and S. J. Richter. 2009. Temperaturesensitive alternative oxidase protein content and its relationship to floral reflectance in natural Plantago lanceolata populations $\rightarrow$ New Phytologist 181:662-671.

$\rightarrow$ Valladares, F., E. Gianoli, and J. M. Gomez. 2007. Ecological limits to plant phenotypic plasticity. New Phytologist 176:749-763.

$\rightarrow$ van Kleunen, M., and M. Fischer. 2005. Constraints on the evolution of adaptive phenotypic plasticity in plants. New Phytologist 166: 49-60.

$\rightarrow$ van Tienderen, P. H. 1991. Evolution of generalists and specialists in spatially heterogeneous environments. Evolution 45:1317-1331.

$\rightarrow$ Via, S., and R. Lande. 1985. Genotype-environment interaction and the evolution of phenotypic plasticity. Evolution 39:505-522.

$\rightarrow$ Visser, M. E. 2008. Keeping up with a warming world: assessing the rate of adaptation to climate change. Proceedings of the Royal Society B: Biological Sciences 275:649-659. von Marilaun Kerner, A., and F. W. Oliver. 1894. The natural history of plants. Blackie, London.

Weinig, C., J. Johnston, Z. M. German, and L. M. Demink. 2006. Local and global costs of adaptive plasticity to density in Arabidopsis thaliana. American Naturalist 167:826-836.

$\rightarrow$ Weis, A. E., and W. L. Gorman. 1990. Measuring selection on reaction norms: an exploration of the Eurosta-Solidago system. Evolution 44:820-831.

West-Eberhard, M. J. 2003. Developmental plasticity and evolution. Oxford University Press, New York.

$\rightarrow$ Wright, S. 1934. The method of path coefficients. Annals of Mathematics and Statistics 5:161-215.

Associate Editor: Tia-Lynn Ashman Editor: Ruth G. Shaw

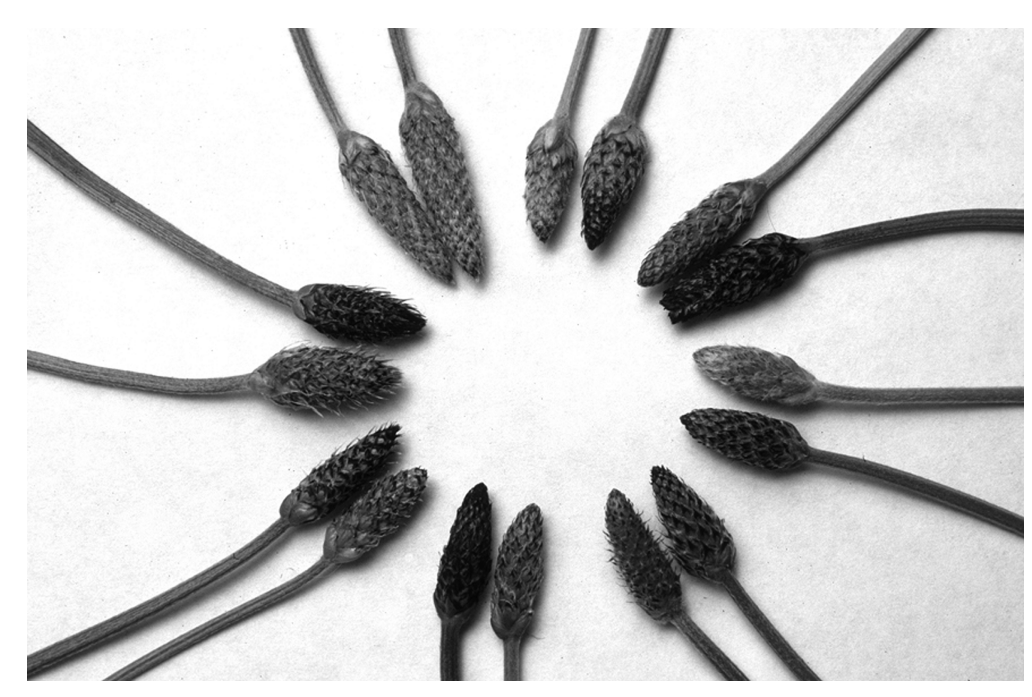

Floral color response to temperature varies genetically. The flower cluster on the left of each pair was produced at a temperature about $7^{\circ} \mathrm{C}$ cooler. Each pair is a distinct genetic individual. Photograph by Daniel J. Smith. 